\title{
Shared PV Production in Energy Communities and Buildings Context
}

\author{
Sérgio Ramos ${ }^{1}$, Zahra Foroozandeh ${ }^{1}$, João Soares ${ }^{1}$, Inês Tavares ${ }^{1}$, Pedro Faria ${ }^{1}$, and Zita Vale ${ }^{1}$ \\ ${ }^{1}$ GECAD - Research Group on Intelligent Engineering and Computing for Advanced Innovation and Development \\ Polytechnic of Porto (ISEP/IPP) \\ Rua Dr. António Almeida, 431, 4200-072, Porto, Portugal \\ E-mail: scr, zah, jan, ivtav, pnf, zav@isep.ipp.pt
}

\begin{abstract}
Across Europe, householders have taken the opportunity to produce their electricity, helping them to reduce their electricity bill as well as reducing carbon emissions, by installing rooftop Photovoltaic Panels (PV) on their buildings. New adequate business models are needed for improving the sharing of PV between consumers in a community. Both technical and economic aspects should be considered in a clear way for consumers to understand and benefit from the community. In this paper, an overview of energy communities is provided to support the innovative PV sharing models for buildings, which are proposed in a way to be clear for community members. The developed concepts are supported by the formulation of the optimization problem to be solved by the community manager.
\end{abstract}

Keywords. BESS, building-integrated PV, energy communities, self-consumption, shared PV.

\section{Introduction}

Renewable energy communities (ECs) involve groups of citizens, social entrepreneurs, public authorities, and community organizations participating directly in the energy transition by jointly investing in, producing, selling, and distributing renewable energy. There are many benefits for the communities involved such as economic development, new job creation, expected cheaper electrical energy bill, self-sufficiency, energy security, and the reduction of carbon emissions [1].

In fact, with the increasing decentralization of electrical energy generation, more individuals and businesses can play a role in the energy system, enabling new business models and ownership structures of energy infrastructure to emerge [1].

The deployment of ECs has been prevented in most countries due to the lack of legislation and regulatory obstacles [2]. However, many countries have been made efforts to adapt the legislation to enable PV sharing at least in the building context.

Recent studies provide some evidence about the economic benefits of sharing PV generation within multiapartment buildings [2-4]. For apartment residents, large roof areas can offer economies of scale in PV installation, while opportunities to aggregate several household loads may create flatter load profiles and increase the selfconsumption with expected economic benefits [5].

In Portugal, recent legislation enables sharing PV generation by publication of Decree-Law 162/2019 of $25^{\text {th }}$
October, which states that collective self-consumers, organized in condominiums of buildings under horizontal ownership or otherwise, or a group of self-consumers located in the same building or zone of apartments or houses, nearby industrial, commercial or agricultural units, and other infrastructures located in a delimited area, which have self-consumption production units, are allowed to share PV consumption.

In this way, the potential of shared PV and the success of energy communities can also be addressed by exploring $\mathrm{PV}$ in one building or multiple buildings.

This paper addresses some conceptual solutions for the installation of PV generation systems in buildings to take advantage of self-consumption by promoting the shared PV generation. The way that energy can be accounted for and the organization of the consumers, as producers of electricity, is also addressed.

The reminded of this paper is organized as follows. In Section 2 a brief overview of the community energy system and shared PV generation is presented. Section 3 addresses several approaches for shared PV generation in buildings and also proposes an optimization model to smooth out consumption peaks in residential buildings. The last section summarizes the concluding remarks and points out some future work.

\section{Community energy system and shared PV generation: a short overview}

With the advent of the community energy system (CES) a set of new players are emerging, namely:

- Independent aggregator: also known as community manager, is a market participant involved in the aggregation activity that is not associated with the customer's supplier;

- Self-consumer: is dedicated to the self-consumption of renewable energy;

- Individual self-consumer: a final consumer who produces renewable energy for his consumption, in his facilities, and who can store or sell electricity with a renewable source of his production, provided that, for non-domestic renewable energy self-consumers, these activities are not the main activity;

- Trader: the entity registered for the sale of electricity, whose activity consists of the wholesale purchase and the wholesale and retail sale of electricity; 
- Renewable energy community (REC): a legal person constituted, with or without profit, based on an open and voluntary adhesion of its members, partners or shareholders, which can be natural or legal persons of a public nature or private, including, in particular, small and medium-sized companies or local authorities, which of independent from their members or partners, but effectively controlled by them;

- Collective self-consumption management entity: the entity, designated by collective self-consumers, in charge of operational management of the activity;

- Market facilitator: a supplier who is subject to the obligation to purchase energy produced by producers under a special regime with market remuneration.

Community energy models are based on the use of renewable energy sources, with a special focus on solar technology [6]. Consumers living in buildings and large condo buildings, or renting living flats, may have a lack of space to install PV panels on their roofs, due to unsuitable roof space. New business models are required to face these challenges. Community energy systems as shared PV generation in building context can address some points to fulfill these new approaches.

In [6], the concept of energy collectives, as a community-based electricity market structure was introduced. The authors found that when prosumers are allowed to share energy at a community level, the overall electricity procurement for the community reflected prosumers' preferences. The proposed work has shown that community members were influenced by a supervisory third party in charge of interfacing with the market and system operator and of guaranteeing the collective common agreements. Several use cases which apply typical principles from the analysis of communication networks and distributed systems to assess community fairness have been simulated.

According to [7], it is possible to analyze the impact of the internal energy exchange fee on integrated community energy systems performance and assets' behavior were also analyzed. According to the proposed model, the performance indicators are generally improved as the internal energy exchange fee is decreased.

According to [8], an organizational framework for a pooled battery resource sharing community of residences using the authors-called Viable Systems Model (VSM) approach was presented. The application of the proposed VSM defined the roles and responsibilities of each stakeholder within the CES for its sustainable operation. The work also demonstrated the use of information and communications technology infrastructures and VSM as a framework for organizational design, control, and management of CES with shared resources in residential communities.

The research work presented in [9], aspired to promote the importance of the prosumer and the sustainable development of a community's energy systems through the incorporation of renewable energy sources in the market and the concept of demand response (DR). The proposed methodology relied on the energy put into the owner grid by self-consumption units which are located in public buildings, so the obtained benefits were shared with all the members of the community, providing demand response, in the proportion of the share of the reduced energy consumption provided.

In [10], two energy sharing models were developed: 1) a welfare optimization, and 2) a game-theoretical (bi-level) model, to understand the effect of sharing distributed generation. It also introduced two types of players: 1) the owner of distributed generation (e.g., solar PV and energy storage), and 2) the consumers. The authors applied both models to a numerical example using data from the electricity market in Texas, USA. The results showed that model 1) allocated energy identically to model 2) with a discriminatory price auction. The allocation of distributed energy resources (DER) and pricing outcomes influenced social welfare outcomes and the distribution of surplus between consumers and the DER owner.

Discussed in [11] is a study of energy and financial flows in five Australian apartment buildings with PV and battery storage using real apartment interval-metered load profiles and simulated solar generation profiles, modelled using an open-source tool developed for that purpose. The authors concluded that using central batteries of 2-3 kWh per apartment increased solar self-consumption by up to $19 \%$ and building self-sufficiency by up to $12 \%$, and have shaved overall building electricity peak demand by up to $30 \%$.

Conceptually, several approaches to the community concept as well as the sharing of solar PV (with or without energy storage) in apartment buildings can be considered. Community and stand-alone buildings solar business models increase the deployment of solar technology in energy communities' environment.

Shared solar energy will enable multiple participants to directly benefit from the energy produced by a solar panel. Indeed, shared solar participants typically benefit from owning or renting a part of a system or purchasing blocks of $\mathrm{kWh}$ of renewable energy generation.

Figure 1 depicts a first approach to the potential of energy communities. Several building groups can deploy a community group that can buy electricity from the power grid or sells generated renewable energy.

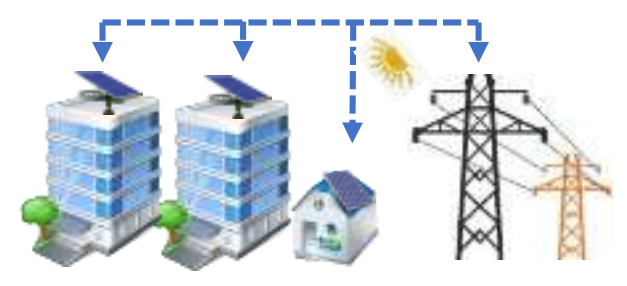

ーேーーーー- Energy and financial flow

Fig.1. Community group (buy and sell)

Figure 2 shows the possibility of having shared solar PV in apartment buildings. Conceptually, the residents may sell the renewable energy generated to the power grid or their neighbor.

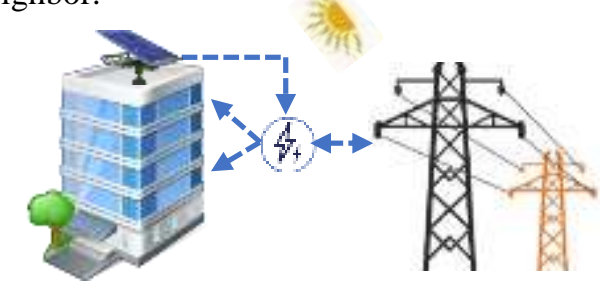

Fig.2. Shared solar PV in an apartment Building 
Another approach to take into consideration is the possibility that a certain local community can benefit from an investment, which all participants can benefit from. Investors can be reimbursed for their investments and local citizens can benefit from access to renewable energy generation. Local communities, as a whole, can benefit from active participation in the reduction of greenhouse gases. Figure 3, illustrates an approach of the communitydriven energy model.

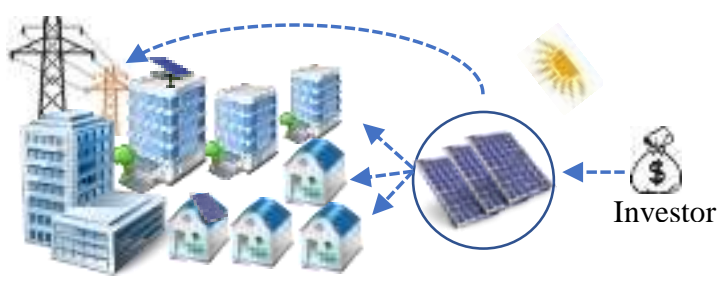

Fig.3. Community group (buy and sell)

Finally, if a lack of space in the top of the buildings to install solar PV panels is an issue, it may be possible to create an offsite shared solar approach, as depicted in Figure 4. This solution makes it possible for people to invest in solar energy together, and for that, allows multiple players (including the community residents) to directly benefit from the electricity produced by one solar array.

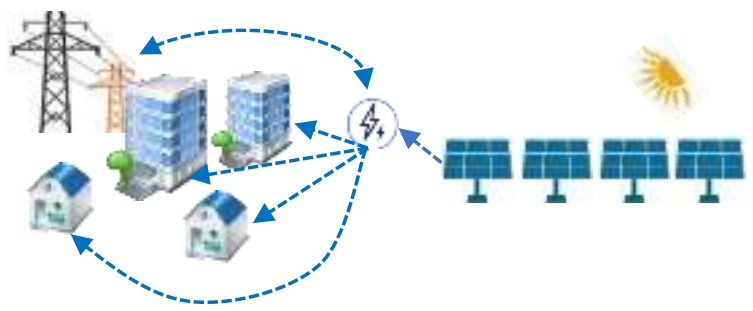

Fig.4. Offsite shared PV in energy community context

Customer demand aggregation may enhance the deployment of shared solar programs reducing technical and financial barriers and limitations. Thus, instead of a single PV array installation by the customer, acting alone, the shared solar models divide the costs among all of the participants, thus facilitating their participation. Investments are even safe for those who cannot stay in one place too long. If a customer moves, his or her solar share can be transferred to a new home within the same utility service territory or sold to someone else [12].

The siting flexibility can also be beneficial to participants since shared PV generation can be located on or off-site thanks to the possibility of having virtual net metering, which enables strategic PV panel placement on commercial and service rooftops of buildings, and municipal areas, contributing to the optimization of the power grid operation and encourage local economic development.

\section{Shared PV Generation in buildings: an approach and optimization model}

All over European Countries, households have taken the opportunity to produce a part of their electrical power, smoothing the load consumption peaks and reducing their electricity bill, apart from their direct contribution to mitigating carbon emissions. This opportunity is provided by the installation of rooftop PV panels on their facilities.
The regulatory aspects created by the European Parliament and of the Council, as well as, by the national legislation of each country, promoted to households the possibility to generate electricity from renewable sources, injecting the power directly in low voltage power networks (with a certain tariff per each produced $\mathrm{kWh}$ ), also promote the self-consumption, and recently the shared renewable generation and the deployment of energy communities.

New models and approaches are required to explore the advantages of the shared renewable generation, in an apartment building context, with a special focus on solar PV technology.

\section{A. Shared PV in collective buildings}

In Portugal, typically, solar PV panels are installed in stand-alone houses. However, apartment buildings have a great potential to utilize solar PV systems. According to the building size and number of flats, the potential rooftop space available to install PV panels can vary significantly. This means that in small buildings (2-3 floors) and medium buildings (4-6 floors) the potential rooftop for PV energy production is likely to exceed common property (CP) demand as well as meet household load consumption demand.

The challenge to install solar PV panels in buildings is identified. PV generation systems among apartments of the same building might be used to sell electricity, for selfconsumption or, even to supply offset apartment loads as well as common properties. Battery energy storage systems (BESS) could have an important role in managing electricity generation in hours in which there is less electricity consumption.

New models and business plans are required to explore the advantages of these new opportunities, presently enshrined in legislation.

Inspired by [5] and [12], it is possible to point out some approaches to take advantage of shared solar PV generation in a building context. Figure 5 shows the typical model for stand-alone self-generation and self-consumption having the opportunity to sell the excess power. Bidirectional meters are required for each unit load. While this solution avoids additional infrastructure requirements, the financial benefits for facility owners are limited. To take more advantage of solar PV generation, BESS can be used to smooth the electricity consumption during peak periods.

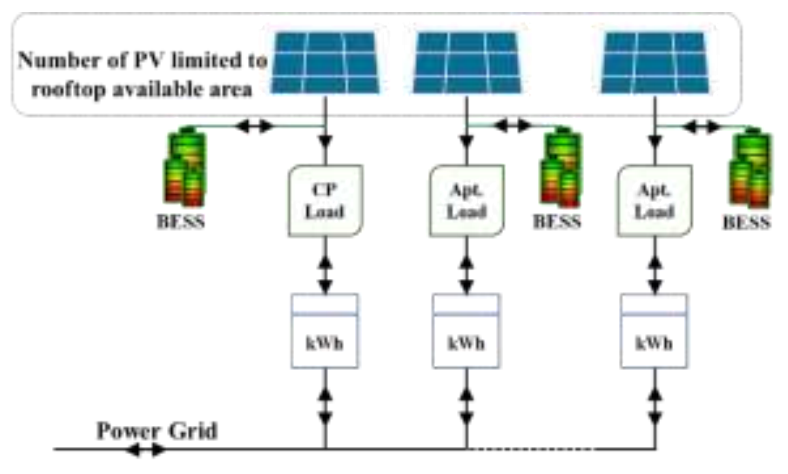

Fig.5. Individual solar PV generation system

Figure 6 depicts another solution based on the shared solar PV generation approach. 


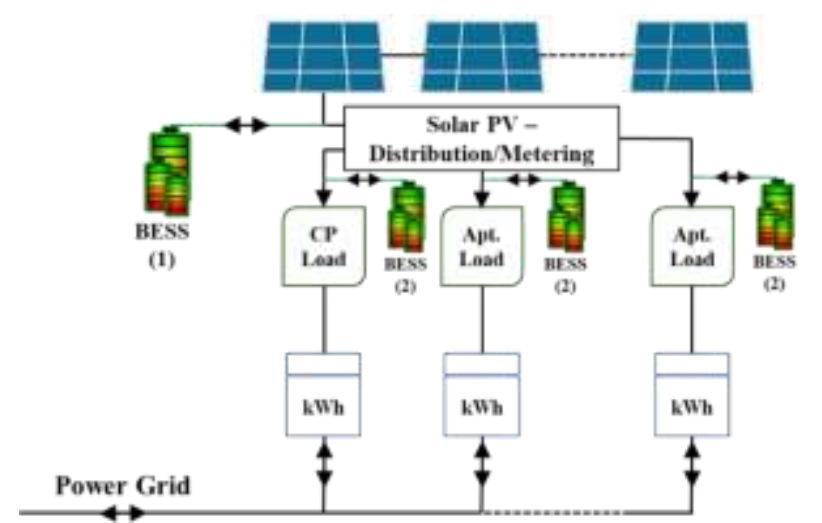

Fig.6. Shared solar PV generation system

Shared solar PV generation may contribute optimization of available rooftop space to install PV panels. Secondary metering is required to distribute among residents the on-site PV generation, while residents can continue to purchase their off-site generation from a certain electricity retailer. The residents can also have BESS to store the generated energy and use it during peak hours to smooth the resident consumption load profile. There are two ways to use BESS: as a centralized storage unit, marked (1) in Figure 6, which means that every resident can use that stored energy, or, as marked (2), using individual storage. In this case, the BESS is charged by the shared PV generation, and then each consumer can use the stored electrical energy accordingly to its consumption preference and load profile.

Figure 7 , presents another solution for sharing the roofing resource to be managed by owners or by an aggregator. The aggregation of solar PV generation may open several business models as well as the participation in the electricity market, or the emerging and so-called local electricity markets.

The distribution of the solar PV generation throughout the building can be assured via an embedded power network, requiring an extra investment in proper infrastructure. The PV generation can be used (and charged by an aggregator or owner's corporation) for each resident.

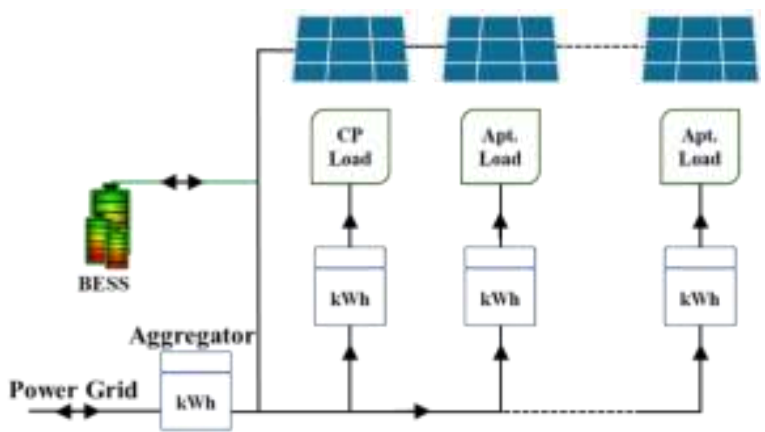

Fig.7. Embedded private power network

Besides selling on-site photovoltaic generation, the aggregator can also stimulate electricity demand aggregation throughout the building to reach advantageous agreements for the electricity demand purchase that can be sold to residents [5].

A centralized BESS can be used to optimize the management of the PV generation according to consumers' load profile, demand response programs, and charging schemes for electrical vehicles (EVs). Another potential of this approach is that it allows some degree of freedom in the apartment contracted power. Even though the legislation does not allow flexibility in the value of the contracted power of low voltage consumers, a third party can manage the building renewable generation, BESS, and EVs charging to enable flexibility in each single contracted power. In this case, an optimization problem is required to minimize the electricity consumption of the entire building.

\section{B. Contracted Power flexibility in building context: An optimization approach proposal}

Shared solar energy generation can open new business plans and new ways of commercial relationships between a set of end-consumers and an energy aggregator or energy supplier, as presented in Figure 7.

If those consumers were settled in a building, the building can be considered as a single client instead of several electricity consumers. Thus, it may have flexibility on the contracted power value of each end-consumer.

The increase of electrical vehicle (EVs) usage brings new challenges to both residents and aggregators concerning the management of the power available to charge EVs. In the near future, the possibility to consider the EVs discharge also brings new challenges and approaches to manage the duration and amount of energy that can be transferred from EVs to the building-embedded power network.

BESS may be useful to manage the PV generation and EVs discharges, to minimize the overall electricity consumption of the building.

Thus, to address these identified challenges, a Mixed Integer Linear Programming (MILP) is proposed to minimize the peak load power demand in a residential building (common property and households). The model takes into consideration the management of solar PV generation accordingly to the charging and discharging process of EVs scheduling, and considers the usage of BESS, taking into consideration the knowledge about consumers' typical load profile. The main idea is to consider the building as a single electricity customer, where an aggregator minimizes the contracted power value of the building taking into consideration the management of PV generation and the BESS/EVs charging/discharging process.

In this subsection, the objective function and constraints of the proposed mathematical formulation are presented, and the most important notation and parameters are shown in Table 1 [13].

Table 1. Nomenclature of the mathematical formulation.

\begin{tabular}{ll}
\hline & \multicolumn{1}{c}{ Indices } \\
\hline$i$ & $\begin{array}{l}\text { Index of time periods } \\
\text { Index of EVs }\end{array}$ \\
\hline$\tau$ & \multicolumn{1}{c}{ Parameters } \\
$P_{g}^{i}$ & The length of interval in each period $i$ \\
& $\begin{array}{l}\text { Active power extracted from the grid in period } i \\
(\mathrm{~kW})\end{array}$ \\
$c^{i}$ & $\begin{array}{l}\text { Penalty factor based on the available PV versus the } \\
\text { consumption in period } i\end{array}$ \\
$P_{s b}^{i}$ & $\begin{array}{l}\text { Active power related to the smart building load } \\
\text { expected in period } i(\mathrm{~kW})\end{array}$ \\
$P_{p v}^{i}$ & Active power related to the photovoltaic generation \\
& foreseen in period $i(\mathrm{~kW})$
\end{tabular}




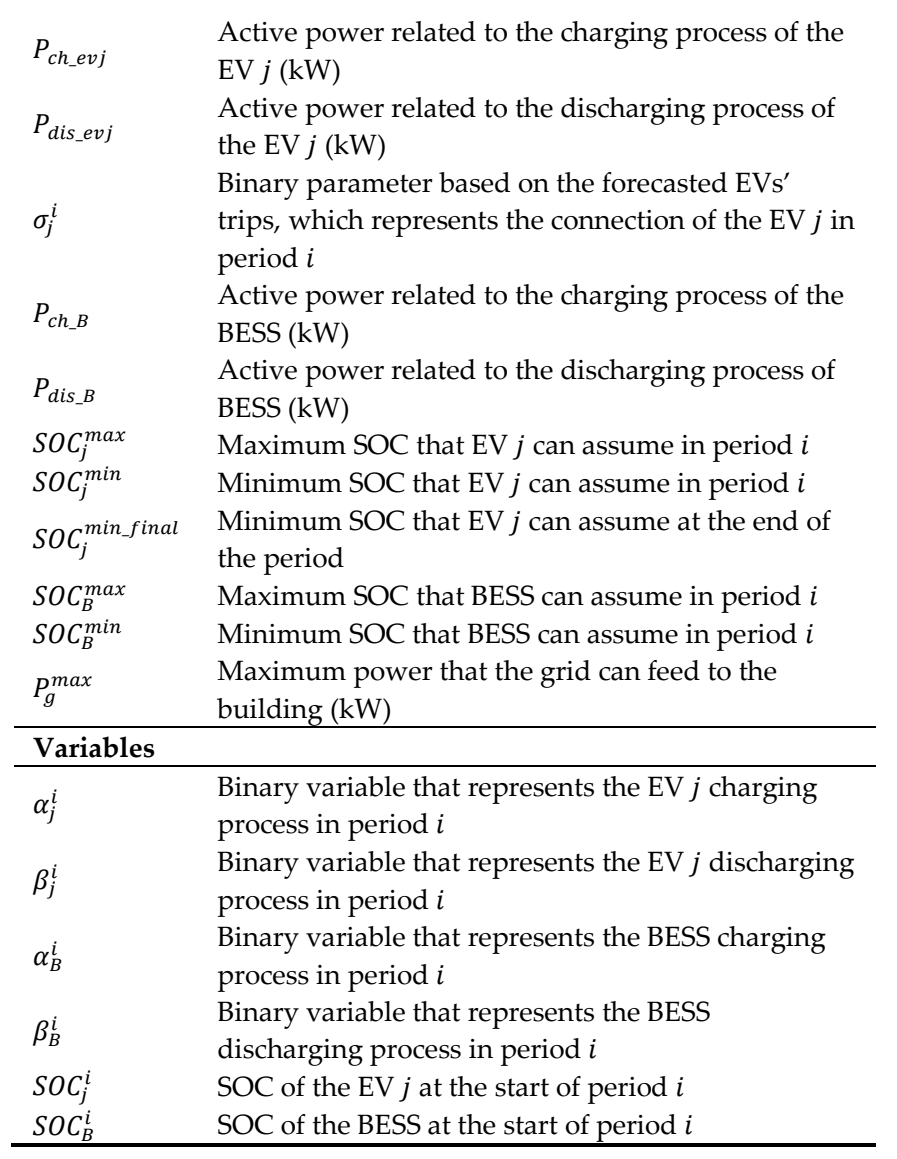

Equation (1), presents the objective function, which intends to minimize the building energy consumption from an external power network.

$$
\min : \sum_{i=1}^{I} P_{g}^{i} \cdot c^{i}
$$

Equations (2) and (3) assure the system power balance. Equation (2) takes into consideration the building load consumption and also the $\mathrm{CP}$ consumption. It is also considered the $\mathrm{PV}$ generation and the charging/discharging process related to EVs and BESS usage.

$$
\begin{array}{r}
P_{g}^{i}=P_{s b}^{i}-P_{p v}^{i}+\sum_{\substack{j=1\\
}}^{n}\left(P_{c h \_e v j}^{i} \cdot \alpha_{j}^{i}-P_{d i s_{-} e v j}^{i} \cdot \beta_{j}^{i}\right) . \\
\cdot \sigma_{j}^{i}+P_{c h \_B}^{i} \cdot \alpha_{B}^{i}-P_{d i s_{-} B}^{i} \cdot \beta_{B}^{i}
\end{array}
$$

Equation (3) represents a cost function of the power availability for EVs and BESS charging and discharging process, in the period $I$. The most appropriate schedule to optimize the EVs/BESS charging/discharging process is achieved.

$$
c^{i}=\frac{\left(P_{s b}^{i}-P_{p v}^{i}\right)}{\min \left(P_{s b}-P_{p v}\right)}
$$

It is necessary to take into consideration a set of constraints to assure the model's effectiveness. The following constraints ensure that the resources do not violate their physical limits and they are not charging and discharging at the same time. Constraints related to the minimum battery state of charge (SOC) and the maximum power value to be consumed from the power grid were proposed. Equation (4) ensures that the physical limitations of the EVs batteries storage capacity are not violated.

$$
S O C_{j}^{i+1}=S O C_{j}^{i}+\sigma_{j}^{i} \cdot\left(P_{c h \_e v j} \cdot \alpha_{j}^{i}-P_{d i s_{\_} e v j} \cdot \beta_{j}^{i}\right) \cdot \tau
$$

Equation (5) is proposed to assure the SOC maximum value of each EV battery that can be assumed in each period $i$ and $\tau$ represents the interval of length in each period $i$.

$$
\operatorname{SOC}_{j}^{i} \leq \operatorname{SOC}_{j}^{\max }, \quad i=0, \ldots, I
$$

The minimum SOC values of the EVs were also defined. Equations (6) and (7) represent the constraints for the minimum value of $S O C_{j}^{i}$ at any period $i$ and in the last period $(\mathrm{i}=I)$. Equation (8) was formulated to avoid the EVs charging/discharging process at the same time.

$$
\begin{aligned}
& S O C_{j}^{i} \geq \sigma_{j}^{i} \cdot S O C_{j}^{\text {min }},(i=1,2, \ldots, I-1), \\
& S O C_{j}^{I} \geq S O C_{j}^{\text {min_final }} . \\
& \alpha_{j}^{i}+\beta_{j}^{i} \leq \sigma_{j}^{i}
\end{aligned}
$$

The formulation for BESS is similar to the approach for EVs constraints and is presented by equations (9), (10), (11), and (12).

$$
\begin{aligned}
& \operatorname{SOC}_{B}^{i+1}=\operatorname{SOC}_{B}^{i}+\left(P_{c h_{-} B}^{i} \cdot \alpha_{B}^{i}-P_{d i S_{-} B}^{i} \cdot \beta_{B}^{i}\right) \cdot \tau . \\
& \operatorname{SOC}_{B}^{i} \leq \operatorname{SOC}_{B}^{\max }, \quad i=0, \ldots, I \\
& \operatorname{SOC}_{B}^{i} \geq \operatorname{SOC}_{B}^{\text {min }}, \quad i=1, \ldots, I \\
& \alpha_{B}^{i}+\beta_{B}^{i} \leq 1 .
\end{aligned}
$$

Finally, equation (13) represents the maximum power value from the grid that can supply the building during each period $i$.

$$
P_{g}^{i} \leq P_{g}^{\max }, i=1, \ldots, I .
$$

Using the proposed mathematical model formulation, and taking into consideration the use of real databases concerning PV Generation, CP and residents load consumption, and also the technical characteristics of the BESS and EVs batteries, it is intended, for future work, to obtain several scenarios (considering the use of BESS or only EVs charging/discharging process) aiming to smooth out the building load consumption and an analysis of the potential benefits gains for end-consumers.

\section{Concluding remarks and future work}

In this paper, an overview of conceptual solutions for the deployment of solar PV generation systems in buildings was addressed. It enhances the advantages of selfconsumption by the promotion of shared PV generation. The way that energy can be accounted for and the organization of the consumers, as prosumers, was also addressed.

Single electricity consumers, collective consumers, and energy communities are facing great challenges supported by recent European and national legislation. In this scope, several approaches for shared PV generation in buildings and also in energy communities were conceptually explored, taking into consideration the possibility of new 
business plans. The use of battery energy storage systems can increase the management of shared PV generation. Some possible solutions were discussed and pointed out.

For future work, and supported by a proposed optimization model, it is intended to investigate several scenarios regarding the management of shared PV generation taking into consideration the use of BESS and EVs, to smooth out resident building electricity consumption.

\section{Acknowledgment}

This work has received funding from FEDER Funds through COMPETE program and from National Funds through FCT under the project BENEFICE-PTDC/EEIEEE/29070/2017 and UIDB/00760/2020 under CEECIND/02814/2017 grant.

\section{References}

[1] Simon Hunkin, Katharina Krell, "Policy Learning Platform on Low-carbon economy". Interreg Europe, Europe Union, August 2018.

[2] Bernadette Fina, Hans Auer, Werner Friedl, "Profitability of PV sharing in energy communities: Use cases for different settlement patterns". Energy, Vol. 189, September 2019.

[3] Fina B., Fleischhacker A., Auer H., Lettner G., "Economic assessment and business models of rooftop photovoltaic systems in multiapartment building: case studies for Austria and Germany". Journal of Renewable Energy, 2018.

[4] Zahra Foroozandeh, Sérgio Ramos, João Soares; Zita Vale. 2021. "Energy Management in Smart Building by a MultiObjective Optimization Model and Pascoletti-Serafini Scalarization Approach". Processes 9, no.2:257. January 2021.

[5] Mike B. Roberts, Anna Bruce, Iain MccGill, "PV for Apartment Buldings: Which Side of the Meter?" Asia Pacific Solar Research Conference, December 2017.
[6] F. Moret and P. Pinson, "Energy Collectives: a Community and Fairness based Approach to Future Electricity Markets". IEEE Transactions on Power Systems, vol. 34, no. 5, pp. 3994-4004, September 2019.

[7] N. M. Alavijeh, C. Alemany Benayas, D. Steen and A. T. Le, "Impact of Internal Energy Exchange Cost on Integrated Community Energy Systems”. 2019 IEEE Sustainable Power and Energy Conference (iSPEC), Beijing, China, 2019.

[8] K. Joshi and K. Ramamritham, "Using Viable Systems Model and Big Data for Community Energy Systems". 2019 International Conference on Smart Energy Systems and Technologies (SEST), Porto, Portugal, 2019.

[9] P. Faria, R. Barreto and Z. Vale, "Demand Response in Energy Communities Considering the Share of Photovoltaic Generation from Public Buildings". 2019 International Conference on Smart Energy Systems and Technologies (SEST), Porto, Portugal, 2019.

[10] A. Fleischhacker, H. Auer, G. Lettner and A. Botterud, "Sharing Solar PV and Energy Storage in Apartment Buildings: Resource Allocation and Pricing”. IEEE Transactions on Smart Grid, vol. 10, no. 4, pp. 3963-3973, July 2019.

[11] Mike B. Roberts, Anna Bruce, Iain MacGill, "Impact of shared battery energy storage systems on photovoltaic selfconsumption and electricity bills in apartment buildings". Applied Energy, Vol. 245, pp. 78-95, July, 2019.

[12] "Community and shared solar". U.S. Department of Energy's Office of Energy Efficiency and Renewable Energy (EERE). Available online (february 2019): https://www.energy.gov/eere/office-energy-efficiencyrenewable-energy.

[13] Zahra Foroozandeh, Sérgio Ramos, João Soares, Fernando Lezama, Zita Vale, António Gomes, Rodrigo Joench, "A Mixed Binary Linear Programming Model for Optimal Energy Management of Smart Buildings". Energies 13(7):1719, April 2020. (10.3390/en13071719). 